\title{
Neurological sequelae in newborn babies after perinatal asphyxia
}

\author{
S. W. DE SOUZA AND B. RICHARDS \\ From the University Department of Child Health, St Mary's Hospital, Manchester, and the \\ Department of Computation, University of Manchester Institute of Science and Technology, Manchester
}

SUMmARY A total of 53 babies, 37 to 44 weeks' gestational age with a history of fetal distress in labour, and severe neurological abnormalities in the early newborn period, were followed up for between 2 and 5 years. Their progress was compared with an equal number of normal babies matched for gestational age, birthweight, sex, and social class, but without a history of fetal distress or delay in establishing spontaneous respiration at birth. In the set of babies with a history of fetal distress no perinatal condition was identified that could predict with certainty the type of neurological status in the newborn period, or the occurrence of neurological abnormality in later childhood. Follow-up disclosed a considerable improvement in function in most of the apparently brain-injured babies. It is suggested that such babies exhibiting apathy initially but subsequently hyperexcitability and extensor hypertonia carry the worst prognosis.

It has long been known that perinatal asphyxia sometimes causes brain damage but there is uncertainty about the sequence of events and prognostic value of abnormal neurological signs exhibited by newborn babies with a history of intrapartum or birth asphyxia. With advances in neonatal care the outlook for babies surviving severe perinatal asphyxia appears to have improved (Scott, 1976; Thomson et al., 1977), making it more difficult to identify the precise role of asphyxia in causing brain damage. The present study was undertaken in a set of neurologically abnormal babies with a history of fetal distress in labour, to find out whether the types of neurological signs exhibited by such babies have any bearing on their outcome in later infancy or childhood.

\section{Methods}

Subjects. Newborn babies, 37 to 44 weeks' gestational age, with a history of fetal distress, were diagnosed as severely neurologically abnormal in the early newborn period by colleagues working at the same hospital, because of the unequivocal presence of abnormal tone (hypertonia or hypotonia), irritability on handling (marked increase in spontaneous activity with alteration in respiration, or crying), a 'cerebral' (high-pitched) cry, or convulsions. These

Received 13 December 1977 babies were also seen by one of us (S.W. De S.). They were born between 1971 and 1975 at St Mary's Hospital, Manchester. All were singletons. The gestational age, calculated from menstrual dates, was checked by reference to ossification centres, fetal biparietal diameter, or maternal uterine size. Fetal distress was diagnosed by the obstetricians when the fetal heart rate was $<120$ or $>160$ beats per minute between uterine contractions, on a number of occasions, with or without meconium-stained liquor. At birth all babies were given routine care and resuscitated if necessary by a paediatrician or midwife. The progress of each baby was followed by regular examinations and relevant laboratory or radiological investigations. A diagnosis of neurological abnormality was made in 55 babies, but 2 of these died by 40 hours of age, during which time only one neurological examination had been carried out. The remaining 53 babies with a history of fetal distress were compared with 53 normal controls matched for gestational age, birthweight, sex, and social class. Control babies did not have a history of fetal distress, and they had established spontaneous regular respiration by 5 minutes of age. After discharge from hospital all babies were seen at an outpatient clinic.

Birthweight. The relationship of birthweight to gestational age was studied using charts constructed by Milner and Richards (1974). 
Birth scores. The condition of the babies at birth was assessed by using a subset of the Apgar scoring method (De Souza et al., 1975). The scores of 0, 1, or 2 were given, respectively, if respirations were absent, gasping, or regular; if heart-rate was undetectable, $<100$ or $>100$ beats $/ \mathrm{min}$; and if colour was whitish, bluish, or pinkish. Therefore a maximum score of 6 or a minimum of 0 was possible.

Neurological examination. This was carried out in accordance with the methods of Prechtl and Beintema (1964) for babies, and Paine and Oppé (1966) for older children. If a visual or a hearing impairment was suspected the child was referred to the departments of audiology or ophthalmology for further assessment. The children have been followed up for between 2 and 5 years. Each child was given an overall rating on a 4-point scale according to the presence and severity of neurological abnormality and resulting handicap (Rutter et al., 1970; Thomson et al., 1977). The four categories are: Category 1: no abnormal neurological findings; Category 2: neurological findings of slight or doubtful significance; Category 3: definite disorder but producing little or no physical handicap; Category 4: definite and obviously handicapping disorder.

\section{Results}

The mean gestational age of the 53 babies with a history of fetal distress was 39.7 and that of the 53 controls 39.9 weeks; the range in each group was 37 to 44 weeks. The birthweights ranged from 2110 to $3823 \mathrm{~g}$. Using the data of Milner and Richards (1974), 44 of 53 babies in each group were appropriate-weight-for-gestational age, the remaining 9 were small-for-dates ( $<10$ th centile).

The 2 babies who died by $\mathbf{4 0}$ hours of age were 38 and 39 weeks' gestational age at birth, and their birthweights, $2840 \mathrm{~g}$ and $3000 \mathrm{~g}$, were appropriate for gestational age.

Four other babies, gestational ages 38-40 weeks, born between 1971 and 1975, who retrospectively appeared to have been severely abnormal neurologically and had a history of fetal distress, had not been referred to us. All 4 babies had died by 48 hours of age.

Antenatal conditions, intrapartum complications, and mode of delivery. Table 1 shows the antenatal conditions and intrapartum complications in the $\mathbf{5 3}$ babies with a history of fetal distress and in the 53 control babies.

The mode of delivery is shown in Table 2. A significantly $(P<0.001)$ greater proportion of babies with a history of fetal distress in labour also had an
Table 1 Antenatal conditions and intrapartum complications

\begin{tabular}{lll}
\hline & $\begin{array}{l}\text { With fetal } \\
\text { distress } \\
(n=53)\end{array}$ & $\begin{array}{l}\text { Controls } \\
(n=53)\end{array}$ \\
\hline Antenatal conditions & 2 & 3 \\
$\quad$ Toxaemia & 1 & 0 \\
$\quad$ Hydramnios & 3 & 3 \\
$\quad$ Fetal growth retardation & 2 & 0 \\
$\quad$ Antepartum haemorrhage & 1 & 0 \\
$\quad$ Placenta praevia & & \\
Intrapartum complications & 1 & 0 \\
$\quad$ Cord prolapse & 6 & 0 \\
$\quad$ Transverse arrest of head & 1 & 0 \\
$\quad$ Compound presentation & 3 & 2 \\
$\quad$ Rapid delivery of head & 2 & 2 \\
$\quad$ Materine dysfunction & 1 & 0 \\
\hline
\end{tabular}

Table 2 Mode of delivery

\begin{tabular}{|c|c|c|}
\hline Mode of delivery & $\begin{array}{l}\text { With fetal } \\
\text { distress } \\
(n=53)\end{array}$ & $\begin{array}{l}\text { Controls } \\
(n=53)\end{array}$ \\
\hline $\begin{array}{l}\text { Unassisted vertex vaginal* } \\
\text { Forceps (Kielland's) } \\
\text { Ventouse } \\
\text { Breech } \\
\text { Caesarean section }\end{array}$ & $\begin{array}{l}7 \\
22(6) \\
1 \\
13 \\
10\end{array}$ & $\begin{array}{l}38 \\
3(0) \\
0 \\
9 \\
3\end{array}$ \\
\hline
\end{tabular}

$* \mathbf{P}<0.001 \chi^{2}$ test.

abnormal delivery. Thus $43(81 \%)$ of 53 babies with a history of fetal distress were born by forceps, ventouse, breech, or caesarean section, compared with only $15(28 \%)$ of 53 control babies born by similar abnormal deliveries. The implication here is that a breech presentation, which selects itself, may often be the cause of the fetal distress during labour. In the case of forceps, ventouse, or caesarean section, the mode of delivery is often the result of the onset of fetal distress.

Condition at birth and onset of regular respiration. In $22(42 \%)$ of 53 babies with a history of fetal distress in labour (duration 12 to $30 \mathrm{~min}$ ), and birth scores 1 or 2 at 1 minute of age, regular respirations were established by 5 minutes of age. In the remaining $31(58 \%)$ babies with a history of fetal distress (duration 10 to $45 \mathrm{~min}$ ), with birth scores 0 to 2 at 1 minute, regular respirations were established between 7 and 60 minutes of age. A birth score of 0 , with no vital signs, was recorded in one baby who received cardiac massage until the apex beat was audible by 4 minutes of age; this baby had taken 22 minutes to establish spontaneous regular respiration.

All 53 babies in the control group had birth scores of 3 to 5 at 1 minute of age; regular respirations were established by 5 minutes of age. 
Clinical conditions in the newborn period. The clinical conditions in the newborn period are shown in Table 3. These conditions were observed in 7 of 53 babies with a history of fetal distress, but in none of the 53 controls. Two babies classified in this table as 'hypoglycaemic' had blood glucose levels $<1 \cdot 2$ $\mathrm{mmol} / 1 \mathrm{l}(22 \mathrm{mg} / 100 \mathrm{ml})$; correcting this hypoglycaemia produced no change in neurological signs. The low blood glucose level was found in a routine test and was corrected immediately. The two hypocalcaemic babies had serum calcium levels of 1.0 $\mathrm{mmol} / 1(4 \mathrm{mg} / 100 \mathrm{ml})$ or $1.2 \mathrm{mmol} / 1(4.8 \mathrm{mg} / 100$ $\mathrm{ml})$. The one baby with infection had radiological evidence of pneumonia, and bacterial pathogens were cultured from blood specimens and throat swabs. An exchange transfusion was carried out on one baby because of jaundice (serum bilirubin 300 $\mu \mathrm{mol} / 1 \mathrm{l}(17.5 \mathrm{mg} / 100 \mathrm{ml})$ associated with severe bruising caused by a breech delivery. The one baby with hyponatraemia had a serum sodium level of $118 \mathrm{mmol} / \mathrm{l}(118 \mathrm{mEq} / \mathrm{l})$.

Neurological characteristics in the newborn period. Thirty-nine babies were referred to one of us (S.W.De S) on the first, 10 on the second, and 4 on the third postnatal day because of a severe neurological abnormality. In the case of neurologically abnormal babies daily neurological examinations were carried out for a 10-day period, but in the case of control babies the examinations extended only to the date of discharge. In 6 babies with a neurological abnormality, in whom signs persisted beyond 10 days, daily observations were carried out until these babies were discharged. The neurological signs exhibited by these babies are shown in Table 4. In babies who were apathetic or hyperexcitable several neurological signs appeared in combinations. Apathetic babies, characterised by a general depression of nervous function, exhibited reduced spontaneous activity, hypotonia, and reduced neonatal responsesincluding traction, rooting, grasp, and Moro responses. Hyperexcitable babies exhibited a low threshold for the Moro response, low frequency wide amplitude tremors, and brisk tendon reflexes. Seven

Table 3 Clinical conditions in the newborn period

\begin{tabular}{lll}
\hline Conditions & $\begin{array}{l}\text { With fetal } \\
\text { distress } \\
(n=53)\end{array}$ & $\begin{array}{l}\text { Controls } \\
(n=53)\end{array}$ \\
\hline Hypoglycaemia & 2 & 0 \\
Hypocalcaemia & 2 & 0 \\
Infection & 1 & 0 \\
Exchange transfusion & 1 & 0 \\
Hyponatraemia & 1 & 0 \\
No. of babies with any one of these & 7 & 0 \\
$\quad$ conditions & 7 & \\
\hline
\end{tabular}

Table 4 Neurological status in the newborn period

\begin{tabular}{|c|c|c|}
\hline Neurological status & $\begin{array}{l}\text { With fetal } \\
\text { distress } \\
(n=53)\end{array}$ & $\begin{array}{l}\text { Controls } \\
(n=53)\end{array}$ \\
\hline \multicolumn{3}{|l|}{ Hyperexcitability ( 32 babies) } \\
\hline $\begin{array}{l}\text { only } \\
\text { and convulsions } \\
\text { and apnoea } \\
\text { and bulging anterior fontanelle } \\
\text { and tube feeding }\end{array}$ & $\begin{array}{r}21 \\
10 \\
4 \\
2 \\
8\end{array}$ & $\begin{array}{l}0 \\
0 \\
0 \\
0 \\
0\end{array}$ \\
\hline \multicolumn{3}{|l|}{ Persistent apathy (12 babies) } \\
\hline $\begin{array}{l}\text { Apathy only } \\
\text { and convulsions } \\
\text { and apnoea } \\
\text { and bulging anterior fontanelle } \\
\text { and tube feeding }\end{array}$ & $\begin{array}{l}8 \\
3 \\
3 \\
1 \\
3\end{array}$ & $\begin{array}{l}0 \\
0 \\
0 \\
0 \\
0\end{array}$ \\
\hline \multicolumn{3}{|l|}{$\begin{array}{l}\text { Initial apathy ( } 7 \text { babies) } \\
\text { Apathy initially but hyperexcitability } \\
\text { and extensor hypertonia } \\
\text { subsequently }\end{array}$} \\
\hline $\begin{array}{l}\text { only } \\
\text { and convulsions } \\
\text { and apnoea } \\
\text { and bulging anterior fontanelle } \\
\text { and tube feeding }\end{array}$ & $\begin{array}{l}0 \\
7 \\
7 \\
7 \\
7\end{array}$ & $\begin{array}{l}0 \\
0 \\
0 \\
0 \\
0\end{array}$ \\
\hline $\begin{array}{l}\text { Normal tone ( } 2 \text { babies) } \\
\text { Normal tone only } \\
\text { and convulsions } \\
\text { and apnoea } \\
\text { and bulging anterior } \\
\text { fontanelle } \\
\text { and tube feeding }\end{array}$ & $\begin{array}{l}0 \\
2 \\
0 \\
0 \\
0\end{array}$ & $\begin{array}{r}53 \\
0 \\
0\end{array}$ \\
\hline
\end{tabular}

of the 19 apathetic babies, after a 2- to 3-day period, exhibited hyperexcitability and extensor hypertonia. The remaining 12 babies continued to exhibit apathy. Thus during a 10-day period these 19 babies exhibited either apathy alone or apathy initially, but subsequently hyperexcitability and extensor hypertonia. Thirty-five babies exhibited hyperexcitability and flexor hypertonia. Only 2 babies had normal tone but they also had convulsions for between 2 and 3 days. Three types of convulsions were observed. These consisted of tonic extension of the trunk and limbs with the baby assuming the decerebrate posture, wide amplitude clonic movements affecting the arms or legs and the face sometimes twitching rhythmically, or myoclonic jerks which occurred in one arm or leg.

A significantly $(P<0.01)$ higher frequency of convulsions, apnoea, bulging anterior fontanelle, and tube feeding were observed in babies exhibiting apathy initially but hyperexcitability and extensor hypertonia subsequently, than that in the remaining babies with a history of fetal distress (Table 4). These conditions were observed in all 7 babies exhibiting apathy initially but subsequently hyperexcitability and extensor hypertonia, but in only 17 of 46 babies with other types of neurological status. The duration of these neurological signs is shown 
in Table 5. A significantly $(P<0.05)$ greater proportion of babies with apathy initially but hyperexcitability and extensor hypertonia subsequently continued to exhibit these neurological signs beyond the tenth postnatal day, compared with that of the remaining babies with other types of neurological status. Three of 7 babies who exhibited apathy initially subsequently exhibited hyperexcitability and extensor hypertonia beyond the tenth day. By comparison, only 3 of 46 remaining babies, with either apathy or hyperexcitability and flexor hypertonia, continued to exhibit these characteristics beyond the tenth day. Thus, babies exhibiting apathy initially but subsequently hyperexcitability and extensor hypertonia had a greater severity of illness.

In an attempt to identify antenatal, natal, or postnatal factors which would predict these types of neurological status in the newborn period, the effects of the following factors were examined: antenatal conditions, cause of onset of labour, intrapartum complications, drugs received during labour, length of labour, duration of fetal distress, mode of delivery, heart rate at 1 minute of age, birth scores at 1 minute of age, time taken to begin spontaneous regular respiration, birthweight, gestational age, sex, and postnatal conditions (Table 3). None of these factors was found to be of predictive value.

Neurological status in the newborn period in relation to neurological abnormalities in later childhood. After discharge from hospital all babies were followed up for between 2 and 5 years. Neurological abnormalities were observed in the fetal distress group (Table 6), but not in the controls. Forty-two $(78 \%)$ of 53 children with a history of fetal distress in whom neurological status had caused concern in the newborn period showed no neurological abnormality at follow-up. Seven (14\%) children had a slight or doubtful abnormality which included squints, febrile convulsions, a head circumference greater than the 90th centile (Westropp and Barber, 1956) between 1 and 9 months of age, hyperactive behaviour, or minor degrees of motor dysfunction. Three $(6 \%)$ children showed definite abnormalities but no handicap -1 child with epilepsy and 2 with nerve deafness.

Table 5 Duration of neurological signs

\begin{tabular}{lrrrr}
\hline Neurological status & $n$ & \multicolumn{3}{c}{ Duration (days) } \\
\cline { 2 - 5 } & & $<5$ & $5-10$ & $>10$ \\
\hline Hyperexcitable with flexor hypertonia & 32 & 11 & 19 & 2 \\
$\begin{array}{l}\text { Apathy } \\
\text { Apathy initially, but subsequently }\end{array}$ & 12 & 4 & 7 & 1 \\
$\quad \begin{array}{l}\text { hyperexcitability and extensor } \\
\text { hypertonia }\end{array}$ & 7 & 0 & 4 & 3 \\
Normal tone, and convulsions & 2 & 2 & 0 & 0 \\
Total & 53 & 17 & 30 & 6 \\
\hline
\end{tabular}

Table 6 Neurological findings in later childhood (2-5 years)

\begin{tabular}{|c|c|c|c|c|c|}
\hline \multirow{2}{*}{$\begin{array}{l}\text { Neurological status } \\
\text { in the newborn } \\
\text { period }\end{array}$} & \multirow[t]{2}{*}{$n$} & \multicolumn{4}{|c|}{ Outcome in childhood ${ }^{*}$} \\
\hline & & $\begin{array}{l}\text { Category } \\
1\end{array}$ & $\begin{array}{l}\text { Category } \\
2\end{array}$ & $\begin{array}{l}\text { Category } \\
3\end{array}$ & $\begin{array}{l}\text { Category } \\
4\end{array}$ \\
\hline $\begin{array}{l}\text { Hyperexcitable with } \\
\text { flexor hypertonia }\end{array}$ & & 30 & 2 & 0 & 0 \\
\hline $\begin{array}{l}\text { flexor hypertonia } \\
\text { Apathy }\end{array}$ & 12 & 10 & 1 & 1 & 0 \\
\hline $\begin{array}{l}\text { Apathy initially, but } \\
\text { subsequently } \\
\text { hyperexcitability and } \\
\text { extensor hypertonia }\end{array}$ & d 7 & 0 & 4 & 2 & 1 \\
\hline $\begin{array}{l}\text { Normal tone, and } \\
\text { convulsions } \\
\text { Total }\end{array}$ & $\begin{array}{r}2 \\
53\end{array}$ & $\begin{array}{r}2 \\
42\end{array}$ & $\begin{array}{l}\mathbf{0} \\
7\end{array}$ & $\begin{array}{l}\mathbf{0} \\
\mathbf{3}\end{array}$ & $\begin{array}{l}0 \\
1\end{array}$ \\
\hline
\end{tabular}

*1 = no abnormal neurological findings; 2 = neurological findings of slight or doubtful significance; $3=$ definite disorder, but producing little or no physical handicap; 4 = definite and obviously handicapping physical disorder.

These 3 children and the 7 in the previous group were making average progress in normal schools. Only one $(2 \%)$ was severely handicapped by spastic quadriparesis, athetoid movements, and epilepsy.

An attempt was made to identify antenatal, natal, or postnatal conditions, including the type of neurological status in the newborn period, that would predict the occurrence of definite neurological abnormality (categories 3 and 4) in later childhood. None, except the type of neurological status in the newborn period, was of any predictive value. Three of the 7 children who in the newborn period exhibited apathy initially, but subsequently hyperexcitability and extensor hypertonia, also had definite neurological abnormalities in childhood (Table 6); including one child severely handicapped by spastic quadriparesis, athetoid movements, and epilepsy. By contrast only one of the 46 remaining children, who had exhibited a different type of neurological status in the newborn period, had a definite neurological abnormality in childhood. This difference is highly significant $(\mathrm{P}<0.001)$.

\section{Discussion}

The long-term outlook in newborn babies surviving severe asphyxia at birth is not as bad as had been thought. Scott (1976) reported a favourable outcome in 17 of 23 severely asphyxiated babies followed up for between 3 and 7 years. Thomson et al. (1977) also reported a favourable outcome in 29 of 31 severely asphyxiated babies seen at between 5 and 10 years of age. In the present study there were no statistically significant differences in the duration of fetal distress, the condition at birth, or the time taken to establish spontaneous regular respiration, between babies who in later childhood had definite neurological 
abnormalities and those who had not. Thus, these three criteria, on their own, cannot be relied upon for predicting the occurrence of neurological abnormalities in later childhood in babies surviving severe intrapartum or birth asphyxia.

Several published reports have shown that perinatal asphyxia increases the risk of handicapssuch as cerebral palsy, mental retardation, epilepsy, or disorders of learning and behaviour in childhood (Berendes, 1975) - but there is still uncertainty about the precise role of asphyxia in causing these conditions since most babies surviving severe asphyxia do so as normal children (Fraser and Wilks, 1959; Benaron et al., 1960; Scott, 1976; Thomson et al., 1977). There are several other perinatal conditionssuch as prematurity, intrauterine growth retardation, apnoeic attacks, hypoglycaemia, or hyperbilirubinaemia - that may also increase the risk of handicaps in childhood. In the present study a higher proportion of babies with a history of fetal distress were born by an abnormal delivery. Some of these deliveries-by Keillands forceps, by ventouse, or by the breech-may be traumatic to the fetus, causing in some such fetuses tentorial tears, or brain-stem or spinal cord injury (Yates, 1959; Towbin, 1960; De Souza and Davis, 1974).

Although neurological examinations in newborn babies are time-consuming the information obtained, by using a standardised method (Prechtl and Beintema, 1964) for term babies, has proved useful in building up a picture of the kind of baby who is more likely to be neurologically abnormal at follow-up. Two previous studies (Brown et al., 1974; Thomson et al., 1977) have reported a higher incidence of feeding difficulties, persistent vomiting, convulsions, hypothermia, a high pitched cerebral cry, or abnormal muscle tone in the newborn period, in children who manifested neurological abnormalities. In the present study there was an increased incidence of similar conditions in newborn babies who were initially apathetic but were subsequently hyperexcitable and had extensor hypertonia. As these babies probably had a greater severity of illness than the remaining ones that exhibited other types of neurological characteristics they also had the worst outcome. It was not possible to identify any factor in their antecedents that could predict with certainty why a poor outcome accompanied 3 out of 7 of these babies.

It has been suggested that the likelihood of permanent brain damage should be seriously considered in babies with a history of cardiac arrest of more than 5 minutes' duration (Steiner and Neligan, 1975), or when spontaneous respiration is not established by 30 minutes of age (Scott, 1976). Steiner and Neligan (1975) have reported that one of 14 babies with a history of cardiac arrest for 5 minutes or less, and 4 of 12 babies with a history of cardiac arrest of more than 5 minutes' duration, manifested quadriplegia or deafness in later childhood. More recently, in a study on the outcome of severely asphyxiated babies, Scott (1976) reported that 2 of 12 babies who had taken 30 minutes or less, and 4 of 11 babies who had taken more than 30 minutes to establish spontaneous respiration were handicapped in later childhood. It is worthy of note that these differences are not statistically significant. The predictive value of cardiac arrest or delay in establishing spontaneous respiration at birth remains unresolved. In the present study, one of 46 babies with a history of having taken less than 30 minutes, but none of 7 that had taken more than 30 minutes to establish regular respiration at birth, was handicapped in later childhood. The one baby with a history of cardiac arrest, lasting 4 minutes, had a favourable outcome.

The authors thank Professor J. A. Davis, Professor J. P. M. Tizard, and Dr J. L. Smart for advice, colleagues in the Departments of Child Health and Obstetrics for permission to use their data, and Mrs Elaine Evans for secretarial assistance.

\section{References}

Benaron, H. B. W., Tucker, B. E., Andrews, J. T., Boshes, B., Cohen, J., Fromm, F., and Yacozynski, G. K. (1960). Effect of anoxia during labour and immediately after birth on the subsequent development of the child. American Journal of Obstetrics and Gynecology, 80, 1129-1142.

Berendes, H. W. (1975). Epidemiology of perinatal injury. In Progress in Clinical and Biological Research, volume 2, pp. 1-21. Edited by K. Adamsons and H. A. Fox. Liss New York.

Brown, J. K., Purvis, R. J., Forfar, J. O., and Cockburn, F. (1974). Neurological aspects of perinatal asphyxia. Developmental Medicine and Child Neurology, 16, 567-580.

De Souza, S. W., and Davis, J. A. (1974). Spinal cord injury in a newborn infant. Archives of Disease in Childhood, 49, $70-71$.

De Souza, S. W., John, R. W., Richards, B., and Milner, R. D. G. (1975). Fetal distress and birth scores in newborn infants. Archives of Disease in Childhood, 50, 920-926.

Fraser, M. S., and Wilks, J. (1959). The residual effects of neonatal asphyxia. Journal of Obstetrics and Gynaecology of the British Empire, 66, 748-752.

Milner, R. D. G., and Richards, B. (1974). An analysis of birthweight by gestational age of infants born in England and Wales: 1967 to 1971. Journal of Obstetrics and Gynaecology of the British Commonwealth, 81, 956-967.

Paine, R.S., and Oppé, T. E. (1966). Neurological Examination of Children. Clinics in Developmental Medicine, No. 20/21. Heinemann: London.

Prechtl, H. F. R., and Beintema, D. J. (1964). Neurological Examination of the Full Term Newborn Infant. Little Club Clinics in Developmental Medicine, Series No. 12. Heinemann: London.

Rutter, M., Graham, P., and Yule, W. (1970). A Neuropsychiatry Study in Childhood. Clinics in Developmental Medicine, No. 35-36. Heinemann: London. 
Scott, H. (1976). Outcome of very severe birth asphyxia. Archives of Disease in Childhood, 51, 712-716.

Steiner, H., and Neligan, G. (1975). Perinatal cardiac arrest: quality of the survivors. Archives of Disease in Childhood, 50, 696-702.

Thomson, A. J., Searle, M., and Russell, G. (1977). Quality of survival after severe birth asphyxia. Archives of Disease in Childhood, 52, 620-626.

Towbin, A. (1960). Pathology of Cerebral Palsy. Thomas: Springfield.
Westropp, C. K., and Barber, C. R. (1956). Growth of the skull in young children. Part I. Standards of head circumference. Journal of Neurology, Neurosurgery and Psychiatry, $19,52-54$.

Yates, P. O. (1959). Birth trauma to the vertebral arteries. Archives of Disease in Childhood, 34, 436-441.

Correspondence to Dr S. W. De Souza, University Department of Child Health, St Mary's Hospital, Manchester M13 0JH. 